\title{
Novel Mutation p.Asp374Val of SERPINC1 in a Turkish Family with Inherited Antithrombin Deficiency
}

\author{
Kalıtsal Antitrombin Eksikliği Olan Bir Türk Ailede SERPINC1 Geninde Yeni Bir Mutasyon \\ (p.asp374val)
}

Deniz Aslan

Gazi University Faculty of Medicine, Department of Pediatrics, Division of Hematology, Ankara, Turkey

\section{To the Editor,}

Antithrombin (AT) is a major inhibitor of blood coagulation. It is a serine protease inhibitor (SERPIN) that degrades thrombin, factor (F) IXa, FXa, FXla, and FXIla. It is constantly active, but the presence of heparan sulfate or the administration of heparins will further increase this inactivation [1]. Inherited AT deficiency (ATD) (OMIM \# 107300) is a rare autosomal dominant disorder associated with an increased risk of venous thromboembolism (VTE), which usually develops in young and middle-aged adults [2].

The AT gene (SERPINC1) contains seven exons and six introns [2]. Approximately 400 distinct mutations in SERPINC1 have been described [3]. ATD is characterized by either a reduced level of circulating protein (quantitative, type I) or by the presence of variant proteins (qualitative, type II) [4]. We herein report a novel mutation, a base pair substitution (c.1121A>T) leading to p.Asp374Val, in SERPINC1 in a patient with inherited ATD presenting with cerebral sinovenous thrombosis.

The proband was a 16-year-old Turkish male with a family history of deep venous thrombosis (DVT). He was hospitalized after two days of recurrent headache. Diffusion magnetic resonance imaging (MRI) and venography showed thrombosis in the right transverse sinus and right sigmoid sinus. He was diagnosed with cerebral sinovenous theombosis.

He had no acquired risk factors such as obesity, infection, immobility, or trauma. Hematological work-up revealed reduced AT activity (8\%; normal range: 80\%-120\%) (STA ${ }^{\circledR}$-Stachrom ${ }^{\circledR}$ AT III Kit). Factor V Leiden (FVL), prothrombin 20210A mutation, presence of antiphospholipid and anticardiolipin antibodies, and protein $\mathrm{C}$ or $\mathrm{S}$ deficiency were excluded. Fibrinogen and thrombin time results were within normal limits. His mother and maternal aunt had been treated for unprovoked DVT during their thirties without thorough investigation of the underlying cause. The remaining family members had no history of DVT. Hematological evaluation of the core family revealed a reduced AT level in the mother (Figure 1). The level of AT in the maternal aunt was not available. None of the family members had liver or kidney disease, and there were no other factors contributing to AT reduction.

The patient was successfully treated with subcutaneous enoxaparin at $1.0 \mathrm{mg} / \mathrm{kg}$ twice a day (adjusted according to

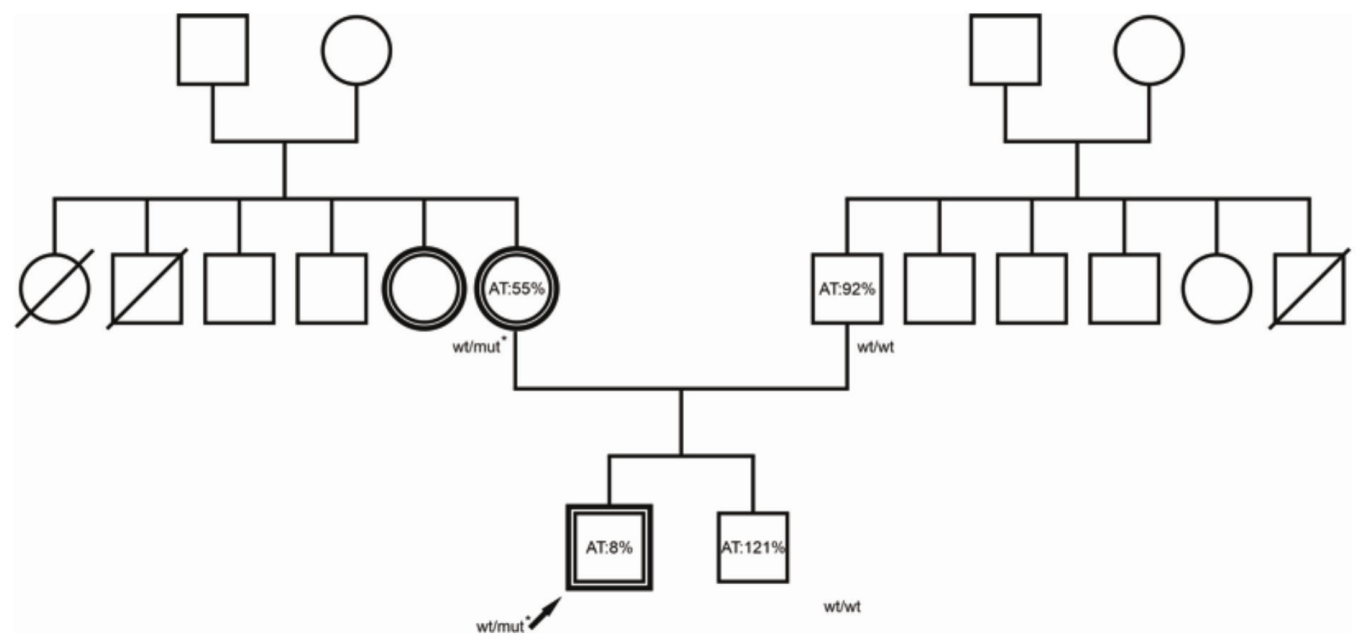

Figure 1. The pedigree of the proband. A double circle or square represents an individual with a definite history of venous thromboembolism. Wt, wild-type; mut*, the p.Asp374Val mutation of SERPINC1, the mutation identified in the proband. 
anti-FXa levels), which was continued for 18 months, when full recanalization of the affected sinuses was observed. The AT level gradually increased over the course of therapy and stabilized at around $60 \%$. The two-year follow-up without prophylaxis was uneventful.

After obtaining informed consent, the exons and intron-exon boundaries of SERPINC1 were studied by direct sequencing [5]. A mutation of p.Asp374Val present in the heterozygous state was found (Figure 2). An in silico study [6] confirmed that this mutation could be detrimental. A search of the published literature revealed that this mutation, named "AT Ankara", has not been previously reported.

VTE is a multifactorial disease determined by a combination of environmental and genetic risk factors. Inherited ATD is a recognized strong genetic risk factor for VTE $[7,8,9]$. A meta-analysis of observational studies showed a high risk of first (16-fold) and recurrent (4-fold) VTE in ATD [10].

This novel c.1121A $>T$, a missense mutation, causes the replacement of a charged amino acid (Asp) with a non-polar one (Val), leading to p.Asp374Val. The change in the amino acid alters the AT protein, leading to a loss of specific inhibitory activity, and increases the risk of thrombosis at a young age. Another mutation at this position (c.1121A>G), leading to p.D374G associated with type II deficiency, has been previously described [11]. Different amino acid changes at the same position, causing distinct clinical phenotypes, have been described in other diseases [12]. The clinical severity of VTE due to AT Ankara and the risk of arterial thrombosis

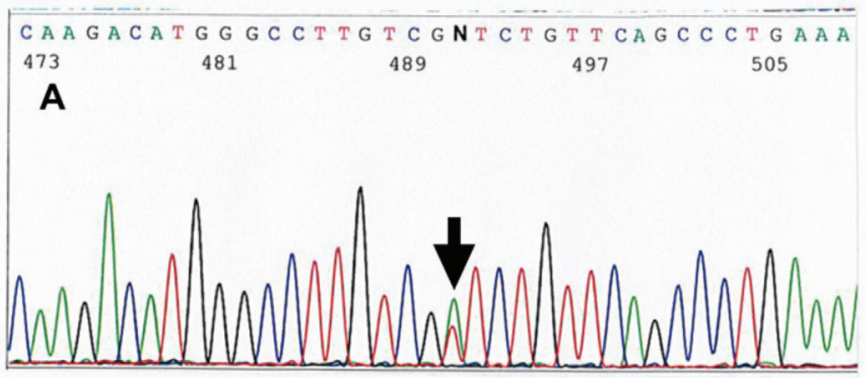

B

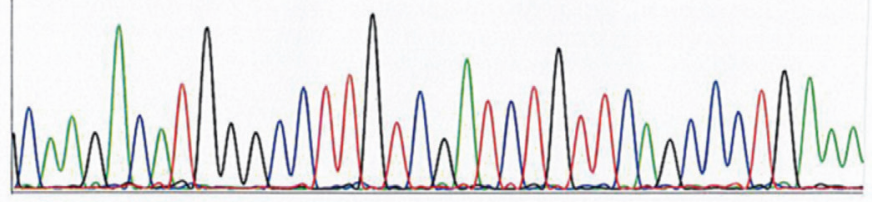

Figure 2. Sequence diagram showing heterozygous c. $1121 \mathrm{~A}>\mathrm{T}$ in the proband $(A)$ and, for comparison, normal sequencing in the father (B). The position of the mutational base is indicated with an arrow. development, if any, are not yet clear; accumulating reports of further cases carrying the same mutation will clarify these points.

Our patient, with a young age and an active lifestyle, was followed without prophylaxis since he had no predisposing factors and the other affected family members had no recurrence. Furthermore, no recurrence was observed in the previous patient with a mutation in the same position despite additional risk factors of arterial hypertension and heterozygous state of FVL [11]. However, management of inherited ATD should be determined on an individual basis and prophylaxis should be considered in cases with predisposing factors.

In conclusion, we have presented herein a novel mutation in SERPINC1 as the genetic cause of VTE in a Turkish family.

Keywords: p.Asp374Val mutation, SERPINC1, Inherited antithrombin deficiency

Anahtar Sözcükler: p.Asp374Val mutasyonu, SERPINC1, Kalıtsal antitrombin eksikliği

\section{Ethics}

Informed Consent: Obtained.

Financial Disclosure: The author declared that this study received no financial support.

Acknowledgments: The author thanks the proband and his family for their willing participation in this study, Dr. Martine Alhenc-Gelas (Hématologie biologique, AP-HP Hôpital Européen G Pompidou, Hôpitaux Universitaires Paris Ouest, Paris, France) for her analysis of the mutation in this family, Yekta Yakal for preparing the figures, and Corinne Logue Can for her language editing.

\section{References}

1. Sarangi SN, Acharya SA. Disorders of Coagulation. In: Lanzkowsky P, Lipton JM, Fish JD (eds). Lanzkowsky's Manual of Pediatric Hematology and Oncology. New York, Academic Press, 2016.

2. Olds RJ, Lane DA, Chowdhury V, De Stefano V, Leone G, Thein SL. Complete nucleotide sequence of the antithrombin gene: evidence for homologous recombination causing thrombophilia. Biochemistry 1993;32:4216-4224.

3. Zhang $H$, Liu $S$, Luo $S$, Jin $Y$, Yang L, Xie H, Pan J, Wang M. Two novel mutations cause hereditary antithrombin deficiency in a Chinese family. Acta Haematol 2020;143:260-265.

4. Patnaik MM, Moll S. Inherited antithrombin deficiency: a review. Haemophilia 2008;14:1229-1239.

5. Picard V, Dautzenberg MD, Villoutreix BO, Orliaguet G, Alhenc-Gelas M, Aiach M. Antithrombin Phe229Leu: a new homozygous variant leading to spontaneous antithrombin polymerization in vivo associated with severe childhood thrombosis. Blood 2003;102:919-925.

6. Richards S, Aziz N, Bale S, Bick D, Das S, Gastier-Foster J, Grody WW, Hegde M, Lyon E, Spector E, Voelkerding K, Rehm HL; ACMG Laboratory Quality Assurance Committee. Standards and guidelines for the interpretation of 
sequence variants: a joint consensus recommendation of the American College of Medical Genetics and Genomics and the Association for Molecular Pathology. Genet Med 2015;17:405-424.

7. Carrell RW, Lomas DA. Alpha1-antitrypsin deficiency--a model for conformational diseases. N Engl J Med 2002;346:45-53.

8. Sarper N, Orlando C, Demirsoy U, Gelen SA, Jochmans K. Homozygous antithrombin deficiency in adolescents presenting with lower extremity thrombosis and renal complications: two case reports from Turkey. J Pediatr Hematol Oncol 2014;36:190-192.

9. de la Morena-Barrio B, Orlando C, de la Morena-Barrio ME, Vicente V, Jochmans K, Corral J. Incidence and features of thrombosis in children with inherited antithrombin deficiency. Haematologica 2019;104:2512-2518.
10. Di Minno MN, Ambrosino P, Ageno W, Rosendaal F, Di Minno G, Dentali F. Natural anticoagulants deficiency and the risk of venous thromboembolism: a meta-analysis of observational studies. Thromb Res 2015;135:923-932.

11. Castaldo G, Cerbone AM, Guida A, Tandurella I, Ingino R, Tufano A, Ceglia C, Di Minno MN, Ruocco AL, Di Minno G. Molecular analysis and genotypephenotype correlation in patients with antithrombin deficiency from Southern Italy. Thromb Haemost 2012;107:673-680.

12. Bradley JF, Collins DL, Schimke RN, Parrott HN, Rothberg PG. Two distinct phenotypes caused by two different missense mutations in the same codon of the VHL gene. Am J Med Genet 1999;87:163-167.

\title{
An Interesting Case: Sunitinib-Induced Microangiopathic Hemolytic Anemia and Nephrotic Syndrome
}

\author{
Illginç Bir Olgu: Sunutinib Illişkili Mikroanjiyopatik Hemolitik Anemi ve Nefrotik Sendrom
}

(D) Veysel Haksöyler ${ }^{1}$, (D) Semra Paydaş²

1 Private Adana Medline Hospital, Adana, Turkey

${ }^{2}$ Çukurova University Faculty of Medicine, Department of Oncology, Adana, Turkey

\section{To the Editor,}

Sunitinib is a heterodimeric oral tyrosine kinase inhibitor that targets a large number of receptors, including VEGFR and PDGFR. Anti-VEGF treatments can cause hypertension, proteinuria, neutropenia, anemia, and thrombocytopenia [1]. It has been shown in animal experiments that vascular endothelial growth factor (VEGF) contributes to the repair of glomerular endothelium in experimental microangiopathia and anti-VEGF antibodies cause proteinuria by glomerular dissociation and downregulation of nephrin receptors [2]. The increase of VEGF levels in the blood 2-3 weeks after thrombotic microangiopathy (TMA) supports the idea of VEGF-mediated repair of the glomerular endothelium [3]. Anti-VEGF treatment may cause thrombosis due to the procoagulant phospholipids released as a result of the disruption of plasma membrane integrity and due to the decrease in the levels of nitric oxide and prostaglandin 12 , which contributes to the production of VEGF [4].

A 54-year-old woman was receiving sunitinib for a metastatic gastrointestinal stromal tumor (GIST). She presented to the clinic 8 months after the initiation of therapy with microangiopathic hemolytic anemia (MAHA) and nephrotic syndrome (NS). Proteinuria $(3.5 \mathrm{~g})$ was detected in the $24-\mathrm{h}$ urine collection. The platelet count was $35000 / \mathrm{mm}^{3}$, white blood cell count was $6700 / \mathrm{mm}^{3}$, and hemoglobin was $7 \mathrm{~g} / \mathrm{dL}$. In the blood smear, normochromic normocytic anemia, diffuse schistocytes, and fragmented erythrocytes were present (Figure 1). Sunitinib was discontinued and methylprednisone was

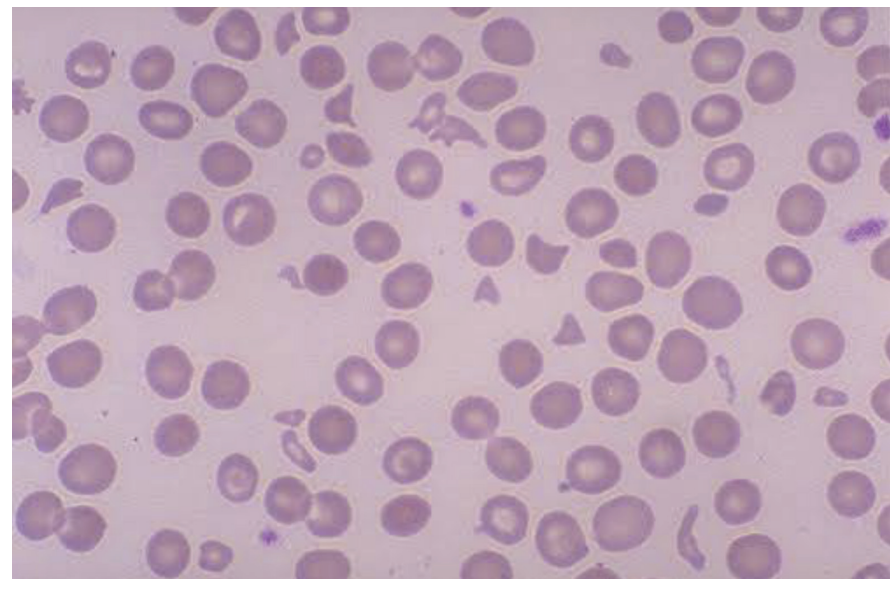

Figure 1. Peripheral blood smear showed rare schistocytes and mild thrombocytopenia. 